\title{
Exploring academic identities of EFL novice writers
}

\author{
Hanna Juliaty \\ Department of English, Faculty of Humanities and Social Sciences, Universitas Kristen Krida Wacana, \\ Jl. Tanjung Duren Raya No. 4, Jakarta, Indonesia
}

\begin{tabular}{|c|c|}
\hline \multirow{2}{*}{\multicolumn{2}{|c|}{$\begin{array}{l}\text { ABSTRACT } \\
\text { In academic writing, undergraduate EFL learners are not required only to apply correct L2 writing } \\
\text { system, but more profoundly, construct and convey ideas in ways recognised in their discipline } \\
\text { as they continuously create and recreate identities as members of their academic community. Such } \\
\text { a process of identity construction shapes EFL novice writers' characteristics and nurture their } \\
\text { growth as writers in the academic environment. This study, thus, aims to explore the portrayal of } \\
\text { academic identities of undergraduate EFL novice writers. Eight Indonesian undergraduate } \\
\text { students of an English Department in a private Indonesian university participated in this study. } \\
\text { The data collected included an autobiography journal, a semi-structured interview and two essay } \\
\text { assignments. The data were analysed qualitatively by employing Ivaničs's (1998) concept of writer } \\
\text { identity, consisting of autobiographical self, discoursal self and authorial self, and Hyland's } \\
\text { (2010) metadiscourse model. The findings reveal that despite numerous writing repertoires } \\
\text { applied to display aspects of autobiographical, discoursal and authorial selves in the learners' } \\
\text { academic writing, the portrayal of academic identities in writing is overall weak due to the } \\
\text { struggles that the learners faced in adjusting and engaging themselves in the academic community } \\
\text { of their discipline. Some recommendations in relation to L2 academic writing practice for EFL } \\
\text { undergraduate students include facilitating students to have more exposure and access into L2 } \\
\text { academic writing culture and academic community of their discipline. } \\
\text { Keywords: Academic writing; EFL; higher education, novice writers; writer identities }\end{array}$}} \\
\hline & \\
\hline $\begin{array}{l}\text { Revised: } \\
\text { 16 July } 2019\end{array}$ & \\
\hline & \\
\hline
\end{tabular}

\section{INTRODUCTION}

In higher education, academic writing is one of the essential skills for undergraduate students to learn. Both in L1 and L2 contexts, regardless of the study major that university students choose, most academic assessments that highly influence their academic success are carried out in the form of writing (Jones, 2011), e.g. essays, reports, research papers and theses. In EFL learning context, novice writers undertake even more challenges in L2 academic writing process as they are required to write in a foreign language, in which many of them are not yet fully proficient (Fareed, Ashraf, \& Bilal, 2016; Shang, 2013).

In writing, learners, intentionally or not, constantly negotiate, create and recreate their identities as writers towards the community in which they belong to (Ivanič,
1998). Such a process of identity construction is important in L2 learning as it shapes the characteristics of learners as L2 writers. When learners are aware of their identities as novice writers in an academic setting, it may foster their growth as writers in their forthcoming academic and professional endeavours (Park, 2013). Yet, many mainstream writing classes around the world still emphasise on teaching L2 written structure than on developing learners' writer identities in an academic setting (Cimasko \& Reichelt, 2011). This study, thus, attempts to explore the L2 academic writing practice of EFL novice writers and how it may influence the academic identities formed and reflected in the writing production of those learners. The results of the study aim to offer insights that may be considered to improve L2 
writing instructions in higher education, particularly in EFL context.

\section{Academic writing}

The act of writing is traditionally regarded as an individual mental and cognitive process done in an isolated and solitary environment (Gillam \& Wooden, 2013). Nevertheless, in academic contexts, writing is perceived as a social practice, in which interactions are built and shaped among the writer and members of the same academic community (Rahimivand \& Kuhi, 2014). In this way, academic writing is different from other writing genres as it is not evaluated based on the preference of the reader, but on the shared view of members in an academic community (Hyland, 2002a).

In general, when undergraduate students are first admitted to the university, they are not familiar with particular academic cultures that they should engage in (Hutchings, 2013). In fact, an academic writing culture is hardly introduced properly to new students, who are simply expected to immediately adapt to it by their institution and instructors, resulting in the feelings of alienation among many new students (Hutchings, 2013; Scanlon, Rowling, \& Weber, 2007). While each discipline may have a different organisation for its academic text, students across disciplines tend to face similar difficulties in adjusting themselves to writing organisation and academic discourse of their discipline since they are not familiar with it (Angélil-Carter, 2000).

In the undergraduate level, essay is the most common academic writing genre for students across disciplines (Hyland, 2009). Similar to other academic writing genres in general, an essay contains a comprehensive development of ideas discussed in three parts: introduction, body and conclusion (Schneer, 2013). Out of these three parts, the body is considered the most important section as it displays the force of one's argument that is sustained through elaboration of ideas and evidence (Morley-Warner, 2009). It is in constructing all these ideas, claims and knowledge that the students face challenges as they are required to use a certain discourse that is recognised by their academic community. Accordingly, they feel that what they write and how they write tend to be restricted (Liming, 2012). Moreover, in the case of EFL learners, they are required to write in L2 instead of L1 and adapt the L2 academic writing culture of their discipline, which new students are not yet familiar with.

All of those factors eventually result in many EFL novice writers having difficulties in L2 academic writing (Jiang, 2011). Since academic writing is a social practice between a writer and members of a certain academic community, many EFL novice writers tend to feel pressured to display particular academic identities in order to be approved by members of the academic community (e.g. L2 Writing instructors) in order to get a decent score for their writing assignments (Hyland, 2009). In longer-term, it may lead to a greater hindrance on their growth into becoming better writers. Hence, it is important for EFL novice writers to be aware of academic identities portrayed in their writing and how it may influence their impact as academic writers to the reader.

\section{Academic writer identities}

In its practice, academic writing across cultures is approached differently in terms of its process and production (Steinman, 2003). Although the rhetorical patterns in writing of different cultures may differ, concerns have been raised in the past decades due to its perceived implications in an academic setting, i.e. the tendency of stereotyping and labelling students based on national identities and cultural differences (Kubota, 2001). In recent decades, this view that culture is static has been shifting towards a recent view that considers writers with the same nationality and culture might write differently. Hence, identity has become a more favourable term to use (Petrić, 2005) because it promotes the individuality of writers in different cultures.

Every writing product does not only portray information of a certain topic but also depicts something about the writer (Ivanič \& Camps, 2001). Dictions, structures, expressions, text organisation and how writers approach and elaborate a topic in writing play an essential part in shaping the impression of themselves as a writer to the reader. Hence, writers are positioned to multiple identities created for them by the discourse they display.

In academic writing practice, in order for writers to engage in social practice and be acknowledged as a member of their academic community, they are required to represent themselves in a way that matches the shared views of the community (Hyland, 2002a). As a result, writers constantly make their own language choices to communicate meanings and convey ideas, and the discoursal choices displayed in their academic texts can signify who they are in the academic community to the reader.

The notion identity is more apt to be used as a plural instead of a singular term because different readers of varied social groups may capture different aspects of writers at the same time (Ivanič, 1994). Ivanič (1998) argues that writer identities are constructed through the writer's autobiographical self, discoursal self and authorial self.

The autobiographical self is the unique sense of the writer as a person brought to the writing (Burgess \& Ivanič, 2010). It includes a writer's history, experience, interests, views of the world, values and beliefs. In academic writing, writers display an autobiographical self through their personal stance on a topic or an issue (Bird, 2013).

The discoursal self is the representation of the writer's self that is inscribed in the text. It consists of identities brought to the writing and identities the writer aspires to be seen by the reader from the text (Burgess \& Ivanič, 2010). A discoursal self is displayed through the writing repertoires used by writers in the text, e.g. use of diction, mechanics and text organisation.

The authorial self refers to the presence that the writer brings to the text as an author. It measures how firm writers sustain their position in the text to the reader 
(Burgess \& Ivanič, 2010). An authorial self is constructed through ways in which writers use language to imply power and claim authority for their writing content (Starfield, 2002). In academic writing, the authorial self validates writers' ownership towards their thinking process and self-confidence to shape and contribute ideas to their academic community.

Writer identities are often examined by evaluating the written discourse of the writer in the produced text. Discourse is established in a text using a set of linguistic and rhetorical devices called metadiscourse, which consists of both interactive markers and interactional markers (Hyland, 2010). Interactive markers are used to assist writers in organising the information flow in the text and guiding the reader through the text. On the other hand, interactional markers are used to help writers establish their self-representation in the text and engage the reader with the content of the text.

As writers sensibly select and apply the markers in their text to communicate ideas to members of a community, academic writing is not simply an act of presenting ideas in a precise writing convention. In fact, it can be regarded as a practice of creating identities as it profoundly relates to the writer's sense of self (Ivanič \& Camps, 2001). Furthermore, identities constructed in academic writing are called academic identities, shaped by a writer as a part of an academic community (Liming, 2012).

In the last few decades, studies on writer identities in academic writing have been done in numerous contexts (Crawford, Pablo, \& Lengeling, 2016). A few studies highlight the cultural framework (e.g. Steinman, 2003) and theoretical bases (e.g. McKinley, 2015) of academic writing and how they impact the construction of writer identities. Some others examine the academic identities of L1 or L2 advanced writers in diverse settings: studying abroad (e.g. Lee \& Maguire, 2011; Park, 2013), doing a postgraduate study (e.g. Ivanič \& Camps, 2001; Liming, 2012) and working in academic community (e.g. Crawford et al., 2016). This study focuses on the exploration of academic identities of EFL novice writers since the literature shows that this group of writers often struggle in this area (Cameron, Nairn, \& Higgins, 2009).

\section{METHOD}

\section{Research design}

This study used a qualitative design. It focuses on behaviours, experiences, interactions and emotions of people (Rahman, 2017) towards certain practices through the analysis of texts or images rather than numbers (Flick, 2014). As this study explores the academic identities of EFL novice writers, it seeks to acquire a deeper understanding of L2 academic writing practice and academic identities of the writers in the naturalistic and interpretive approach. In addition, some studies (e.g. Lee \& Maguire, 2011; Liming, 2012; Park, 2013) that focused on analysing writer identities in academic setting were conducted by using qualitative inquiry. Due to these factors, the qualitative design was viewed suitable for this study.

\section{Participants}

As this study explores EFL novice writers' academic identities in their academic writing practice, the participants of this study were EFL learners with knowledge and experience in L2 academic writing and with sufficient L2 proficiency in writing. The two criteria were used to select the participants as the literature discussed in the previous section reports that students who engage in academic writing are familiar with the practice in the first place (Angélil-Carter, 2000; Hutchings, 2013), and that students with lower L2 proficiency might use very limited discoursal choices in writing because of the lack of L2 knowledge (Shang, 2013).

Based on the criteria, eight EFL learners of an English Department from an Indonesian private university were selected to participate in the study. They just started their fourth semester when they partook in this study, and their age ranged between 18-20 years old. Prior to the study, they had completed three compulsory Writing courses (namely Writing I, Writing II and Writing III) in the previous three semesters, in which academic writing was taught. This shows that the students had already had some knowledge with academic writing practice in their discipline. Also, an observation of their writing assignments in the previous three Writing courses indicated that their L2 proficiency was at least adequate.

\section{Data collection}

The data collected for this study consisted of an autobiography journal, a semi-structured interview and two writing assignments in the form of argumentative and persuasive essays.

The autobiography journal was collected in the beginning. The students were asked to reflect and briefly narrate their L2 learning and L2 writing experiences prior to and during their study at the university. A few questions were included in the autobiography journal sheet to guide the students in their reflection.

After the students submitted the journal, they participated in a semi-structured interview. Due to the time restriction and clashed schedules, they were divided into two groups; each group was interviewed separately. The interview aims to clarify the information in the journal and to provide further information on the students' prior knowledge and perception of their L2 academic writing practice. In conducting the interview for each group, I was assisted by my research assistants. Prior to the interview, I prepared a set of interview questions and trained my assistants to practice their roles as moderators and interviewers. Moderators had duties to open and close the interview, while interviewers had duties to read out the set of questions, ensure that the students alternately answered the questions, and elicit or clarify unclear answers. On the other hand, I took the role as a facilitator, whose responsibility was to explain 
questions that the students found unclear and to assist the interviewers in eliciting the student answers. Each interview lasted around 60-90 minutes and was audiorecorded.

The third collected data were persuasive and argumentative essays of 400 to 1000 words. The essays had been written by the students during the Writing III course in the previous semester and were compiled for this study. The essays were selected among other essays that the students had produced in the course because persuasive and argumentative essays are most commonly written in many academic disciplines (Schneer, 2013), mainly in social and arts majors. As students are required to express and develop academic knowledge, critical thinking and reasoning skills to some extent in those essays (Hyland, 2009; Jones, 2011), the essays were a fitting instrument for the study.

\section{Data analysis}

The three types of data for this study were analysed through several steps of qualitative method using triangulation. Firstly, the semi-structured interview was transcribed and read a few times with the autobiography journal to enhance the comprehension of the students' background and prior knowledge of their L2 learning experience and academic writing practice. Both data from the interview and journal were coded based on the recurring major themes of Ivanič's (1998) concept of writer identities, which later were organised in autobiographical self, discoursal self and authorial selfclassification table.

Secondly, student essays were read and colourcoded based on the metadiscourse model (Hyland, 2010). After that, the results were organised and tallied in a table to find out the frequency of metadiscourse markers in the essays. Afterwards, the essays were reread, this time focusing on the discourse in the texts, and coded based on the recurring major themes of Ivanič's (1998) concept of writer identities. In this second coding step, the metadiscourse table was used to assist the analysis of the student discourses. The results from this coding were organised in another table of autobiographical self, discoursal self and authorial self.

Finally, the analysis results gained from the journal, interview and essays, which were compiled in two tables of autobiographical self, discoursal self and authorial self, were compared, cross-verified and interpreted in order to conclude the portrayal of academic identities in the student essays.

\section{FINDINGS AND DISCUSSION}

The findings show that the novice writers shape numerous academic identities as reflected in their L2 academic writing, e.g. role identities as an average student, a knowledgeable person, an inexperienced member of their academic community, a reporter and a biased judge. All these numerous and sometimes contradictory identities reflect their autobiographical self, discoursal self and authorial self as novice writers in their L2 academic setting.

\section{Autobiographical self}

An autobiographical self portrays life history, interests, values and beliefs of a writer, which possibly influence the construction of writer identities in the writing production (Burgess \& Ivanič, 2010). From the data, the EFL novice writers displayed an autobiographical self as an average student from the lower or middle socioeconomic background, with average literacy practice and little engagement to academic writing. The academic identities were implied in the essays through a number of ways.

Firstly, autobiographical self was exhibited in the way the students selected a topic for the essays (Bird, 2013). As an example, in their persuasive essay, the students were required to present a debatable topic of their choice, take a stance in the debate, and convince the reader about the stance so that the reader may accept or at least positively consider agreeing with them. In fulfilling these requirements, the students drew ideas for their topic based on lifestyles, hobbies and issues related to language learning that they learnt in the class, as shown in Table 1.

Table 1. List of topics in the persuasive essay

\begin{tabular}{ll}
\hline \multicolumn{1}{c}{ Students' Chosen Topics } \\
\hline S1 & Do children need to learn English? \\
S2 & Is milk good for adults? \\
S3 & Should students take a part-time job? \\
S4 & Are gadgets beneficial for children? \\
S5 & Is writing a leisure activity or a work? \\
S6 & Is it okay to consume instant noodles? \\
S7 & Is gaming a useful pastime? \\
S8 & Is green tea good for health? \\
\hline
\end{tabular}

These topics are simple and greatly related to what they normally experienced in their daily life and discussed or learnt in their academic discipline; thus, the topic selection was highly inclined to their interests and experiences as university students.

In addition, although it may not always be clearly evident, the topics closely related to the students' experiences may also indicate their personal background indirectly, such as their socio-economic background, as shown in the following excerpt from the persuasive essay by S7:

"... we are required to work hard to fulfil the needs of our daily life, improve the talent and ability... and also to overcome the problems that are faced. These skills will be sharpened through the strategies in playing games... The examples of games that are created to sharpen and train someone's mindset are SimCity, Harvest Moon, Hayday and Clash of Clans."

In the excerpt, S7 argued that playing online games was not a bad pastime and presented a positive effect of it. Moreover, she mentioned some popular online games. As she took a stance on the positive side of playing games, it may indicate that she liked to play online games as well. Playing online games requires computerised and gaming kit, or at least a smartphone with an internet connection, which is not all cheap for some people; this 
may show that the student probably came from a family with at least middle socio-economic background. This was indirectly hinted in the journal as well, where S7 wrote: "My parents supported me by taking me to an English course since I was in primary school." As her parents were able to enrol her to an English course for years ever since she was still in elementary school, it showed that her family most likely came from at least the middle socio-economic background.

Secondly, the students' autobiographical self is indicated in the length of the essay that they wrote. The students were required to write between 500-700 words for each of the essay assignments in their Writing III course. However, the essays collected for this study showed that 3 students wrote less than was required (S2, S6 and S8), 2 students wrote within the word limit (S1 and S3), and 3 other students wrote more than the word limit (S4, S5 and S7). In academic writing practice across disciplines, students of hard science majors tend to write less than those of social and arts majors because of the nature of their disciplines (North, 2005). In this study, the word limit given in the essay assignments was considered average (not too little nor too many) for the English Department students. Thus, the failure to fulfil the minimum word limit in the essays may hint a writing problem faced by the students, e.g. difficulties to form fluent and accurate L2 sentences (De Haan \& van der Haagen, 2013), limited knowledge on the essay topic (Okasha \& Hamdi, 2014), or little engagement with the writing task (Erkan \& Saban, 2011). From the interview, it was confirmed that three students who wrote less were less engaged in the essay writing than the other peers who managed to write within and beyond the word limit. The less-engaged students explained that they usually wrote for assignments only, while the other peers wrote occasionally for pleasure.

In relation to L2 writing engagement, in the interview session, the students who wrote less admitted that they had low motivation for academic writing. Surprisingly, even though the other peers with more writing practices had a more positive attitude towards the essay writing, their motivation to write the essays was predominantly extrinsic than intrinsic. They explained that they made extra efforts to achieve the word limit requirement as it was one of the assessment criteria, and they hoped that by doing so, it would increase their score for the essays. This tendency that the students showed is consistent with previous research that mentions some students would attempt to be a part of academic community as long as it could get them good grades for the assignments (Ivanič, 1994).

Such lack of intrinsic motivation in L2 academic writing was not only influenced by the students' literacy practice but also caused mostly by unfamiliarity with L2 academic writing practice of their discipline (AngélilCarter, 2000; Hutchings, 2013; Scanlon et al., 2007). From the journal and interview, it was found that the students thought that the essay writing in university was different from the essay writing practice in their high school years. For instance, they shared that in high school, the essay writing was mostly about describing and summarising materials, while in university, it was mostly about positioning themselves in a certain way that was proper to the reader. Consequently, they found that it was challenging and difficult to express themselves freely in writing since there were many restrictions in academic writing rules that they were required to follow (Liming, 2012).

In addition, in relation to the difficulties in making correct L2 sentences, the students who wrote less did not face more problems to write correct L2 sentences than their peers who wrote within and beyond the word limit. The students still made grammatical mistakes regardless of the number of words they wrote in their essays; however, the mistakes can be considered minor since they did not interfere with the reader's overall comprehension of the texts.

From these findings, it can be concluded that the autobiographical self of EFL novice writers was reflected in their essays through the topic selection and length of the writing production. Moreover, the autobiographical self reflected in the essays was affected by the students' life histories, social background, personal interests and L2 academic writing practice that they had experienced up until the moment of the essay writing (Bird, 2013; Ivanič, 1998; McKinley, 2015). This is in line with the existing literature (e.g. Burgess \& Ivanič, 2010) that argues that writers bring a representation of themselves that are shaped through social actions and experiences into their writing.

\section{Discoursal self}

A discoursal self shows a self-representation that a writer, intentionally or unintentionally, inscribes in the text for the reader (Burgess \& Ivanič, 2010). It means that there are at least two possible identities that may emerge from the discourse in writing: the identity that the writer desires to show to the reader through her written discourse and the identity of the writer that the reader perceives based on the written discourse displayed in the text. From the discourse in the essays, the EFL novice writers displayed contradictory identities. On the one hand, they aspired to be seen as an experienced and knowledgeable person who attempts to educate and persuade the reader on some topics. On the other hand, from the discourse, they also displayed another role identity as an inexperienced member of their academic community (Ivanič, 1994).

\section{Experienced and knowledgeable person}

In the essays, the students showed an aspired persona for the reader to perceive, which was an experienced and knowledgeable person in regards to the subject matter of the essays. This was done intentionally as they aspired to show the persona to the reader. The persona was reflected in two ways: by attempting to elaborate the discussion of the subject matter extensively, e.g. through the use of definition, direct quotations, facts and examples, and by using various interactional markers in order to engage with and persuade the reader. 
In academic writing, writers can include information from other sources or references in order to support or elaborate on the arguments presented in their text (Rahimivand \& Kuhi, 2014). In their essays, the students included citations from numerous sources. An instance of this can be found in the persuasive essay of $\mathrm{S} 1, \mathrm{~S} 3$ and S4, as shown respectively in the following excerpt:

"According to Cambridge Advance Learner's Dictionary (2008), cooperation is when you work together with someone or do what they ask you." (definition)

"According to UN official website, there are 193 countries that have joined the UN and collaborate together to create a union and promote peace today." (factual information)

"Parents are the ultimate role models for children... No other person or outside force has a greater influence on a child than the parent. - Bob Keeshan" (direct quotation)

In the interview, the students mentioned that the main reason for them to use information from other sources was actually not to present evidence that can strengthen their arguments, but to help them establish a pleasing persona to the reader. They thought that by presenting extensive information, it would increase the reader's interests to read their essays and to perceive them as someone with knowledge and experience.

In addition, in the interview, the students also admitted that in positioning themselves for the arguments in the essays, they liked to imitate a mature, experienced and intellectual person who attempted to explain the subject matter in the essay to a less knowledgeable and less experienced reader, often in a very serious and exaggerating way. An instance of this can be found in the following excerpt of S1, S5, S6 and S7's argumentative essay:

"This world will not be able to provide enough food for everyone and hunger will happen everywhere."

"If the issue is not crucial enough, FAO would not have been tried so hard spreading the awareness."

"If we are hungry but we do not want to eat rice, we can replace it with taro, potato, corn cassava or sweet potato."

"Everyone's life is precious, we must come together to create a healthy world."

From the excerpt, it can be noticed that the students attempted to persuade and convince the reader to agree with them, e.g. by using the first-person plural pronoun we (to involve the reader or promote group solidarity), by using particular dictions and structures that urged the reader to learn from them, and by intensifying the proposed arguments through either overgeneralisation, overstatement, or exaggeration (Hyland, 2005). The students used the pronoun we frequently in the essays; in fact, L2 novice writers, particularly Asian ones, are believed to prefer using we than $I$ to involve the reader since the plural pronoun is less direct than the singular one (Hyland, 2005). Based on the data recapitulation of the interactional markers in the student essays, it was found that the student discourse tends to show high engagement and persuasion to the reader through the use of boosters (15.61\%), e.g. must, definitely and it is proven, reader-oriented markers (14.25\%), e.g. you, your, we, our and us and writer-oriented markers (13.71\%), e.g. I, me, my, we, our and us.

In summary, the student aspiration to be viewed as an experienced and knowledgeable person by the reader may have been driven from the pressure of wanting to be recognised and approved by members of their academic community, e.g. Writing instructors who read and assess their essays (Hyland, 2005). This is in line with previous studies (e.g. Burgess \& Ivanič, 2010) that reports that when novice writers perceive the reader to hold power over them, they tend to attempt to give the positive impression that could align with the reader's values and expectations.

\section{Inexperienced member of their academic community}

Other than the aspired persona intentionally displayed by the students, the discourse in the student essays reflected another role identity, which was an inexperienced member of their academic community. This identity, which seems to be reflected unintentionally, was displayed through the L2 writing repertoire of the students, i.e. the essay format, the structure of ideas and arguments, and the use of rhetorical questions and academic vocabulary.

For the essays, the students displayed a similar format as required for the Writing III assignments: introduction, a body consisting of three main arguments and conclusion. This essay format is common in various academic writing contexts (Liu \& Furneaux, 2013; Schneer, 2013). In applying the essay format, in the interview, the students admitted that they did not encounter major difficulties as it was primarily a technical matter. Since they followed the required essay format, they were conforming to L2 academic writing culture and displaying themselves as a member of their academic community (Liming, 2012).

In contrast to the format, the structure of ideas and arguments presented in the essays was organised in a more complex way that indicated the students' lack of knowledge on L2 academic writing culture. Such content organisation was shown in the introduction and body of the essays. The students tended to start the introduction quite similarly, where the topic sentence generally was written in a broad statement not closely connected to the topic discussed in the body. An example of this is shown in Table 2, taken from the introduction of S7's argumentative essay.

Table 2. Idea flows in an argumentative essay

\begin{tabular}{cl}
\hline Idea & \multicolumn{1}{c}{ Introduction } \\
\hline 1 & $\begin{array}{l}\text { Health is important for people to stay alive in the } \\
\text { world. }\end{array}$ \\
2 & $\begin{array}{l}\text { Each country in the world has its own health } \\
\text { problems. }\end{array}$ \\
3 & $\begin{array}{l}\text { Health problems can be caused by diseases and } \\
\text { natural disasters. }\end{array}$
\end{tabular}


4 People in the world need each other to meet their needs.

$5 \quad$ WHO is a world organisation that deals with health issues.

In the argumentative essay, S7 aimed to discuss the importance of global cooperation in the medical field. Yet, instead of stating the topic directly to draw the reader's attention to the subject matter (international cooperation in the medical field), she introduced the topic and the subject matter by mentioning how health is very important for people to live. This kind of broad statement and indirect idea flow is often found in writing productions of Asian EFL writers (Kuntjara, 2004; Qin, 2017). In L2 academic writing, it is important for writers to be precise with words and direct with their idea elaboration (Javdan, 2014). Thus, writers are accountable to facilitate the reader to focus on the topic from the start of the essay, i.e. the introduction. In this study, most students failed to do this as they tended to present an overly general and indirect pattern of idea elaboration, which was mainly affected by their own L1 writing repertoire (Javdan, 2014).

Moreover, in addition to being able to present and discuss three arguments in the essays, the students did not organise them with adequate coherence. In the essays, they managed to elaborate the main arguments to an extent to support the stance on the subject matter. Yet, the arguments were not linked to one another in a sensible relationship, e.g. based on a chronological pattern, a cause and effect connection or order of importance. Consequently, each argument in the essay appeared to stand alone and seemed like an isolated subject matter instead of a logically developed stance (Wingate, 2012). This was also indicated by the lack of interactive discourse markers in the student essays, i.e. frame markers $(3.51 \%)$ and endophoric markers $(0.45 \%)$. Frame markers are used to show discourse acts, stages and orders in the idea development, e.g. additionally, finally and to conclude, whereas endophoric markers are used to locate specific part or information in the text, e.g. previously or as mentioned before (Hyland, 2010). From the essays, the students rarely used these markers to organise and connect arguments in a sensible relation. As a result, the overall essay contents lacked of coherence. One of the likely reasons for this was because the students were not sufficiently familiar of ways to organise the contents in L2 academic writing to improve the clarity and coherence in their writing (Hyland, 2005).

In addition to the essay format and argument organisation, the students' identity portrayal as an inexperienced member of the academic community was also reflected in the way they used rhetorical questions in the essays. A few occurrences were mainly used to define keywords and introduce the main idea. These rhetorical questions were written in different parts of the student essays and always followed by straight answers. As an example, in the introduction of the persuasive essay where S4 introduced his essay topic of the benefits of using gadgets for children, a rhetorical question was presented as follow:

\begin{abstract}
"What is gadget? According to Oxford Dictionary, gadget is a small mechanical or electronic device or tool, especially an ingenious or novel one." (smaller font size because the previous and later examples or excerpts are also in smaller font; add a space after the excerpt)
\end{abstract}

In the excerpt above, S4 thought defining the keyword gadget was essential since his essay would discuss the benefits of using gadgets for children. Nevertheless, instead of directly writing the definition, he used a rhetorical question. It may function as an interactional device to engage with the reader (Hyland, 2002b); still, the L2 academic writing culture discourages the use of rhetorical questions (Hinkel, 1997) since they tend to be artificial. Any question displayed in L2 academic writing has to show a genuine inquiry of the writer on the subject matter, and thus, there is usually a process that one needs to undertake to answer it, which commonly is presented in the body paragraphs (MorleyWarner, 2009). This process of formulating an answer for the inquiry is where a writer practices logical and critical thinking to understand, evaluate and draw the conclusion of the subject matter in the essay. In the excerpt, as S4 used the rhetorical question and answered it directly, it did not lead to a process that showed his thinking process; thus, it appeared to be more artificial than genuine.

Additionally, as the term gadget has become a common word in L1 and L2 for Indonesians or others in general nowadays, it may not be crucial to provide a definition of it in the essay. In L2 academic writing, definition of terms and keywords is provided when the words are not widely known or potentially contain different meaning in a specific context. Since S4 defined a common vocabulary that was already well known, the definition did not provide a new insight for the reader; therefore, it lacked meaningful contribution, and it may be perceived as prolix or ineffective by the reader (Intaraprawat \& Steffensen, 1995). This may be caused by the students' lack of knowledge or focus on the audience or reader of their essays. When they know the target audience or reader for their essays, they can establish a common ground and determine what information and supports will be essential to be included in their essays (Intaraprawat \& Steffensen, 1995).

Lastly, the identity as an inexperienced member of the academic community was also shown in the limited numbers of L2 academic vocabulary found in the student essays. The words were checked and identified via the online Academic Word List (AWL); the frequency of L2 academic words in the student essays was only $5.83 \%$ of the total words written. Some of the academic words included in the student essays were cooperation, crucial, eliminating, globalization and inevitable.

The scarcity of L2 academic vocabulary in the essays suggested that the students had not yet acquired sufficient academic words to be integrated into their academic discourse. In the journal and interview, it was mentioned that they started learning academic words in the university. During their high school years, the L2 writing practice mainly consisted of diary entries, short stories and summaries. These texts are commonly 
informal; hence, they can be written using general vocabulary. However, L2 writing practice in university required them to acquire academic words and use them in writing. Since academic writing is a social practice of a writer and other members of an academic community, the writer needs to adjust himself or herself according to the discourse recognised by the community (Rahimivand \& Kuhi, 2014). For the EFL novice writers in this study, it was not easy to access the academic discourse and vocabulary of their community as it had been only three semesters since they started learning in their department and got exposed to the academic culture of their discipline (Ivanič, 1994).

In summary, it can be concluded that the students' L2 writing repertoire, shown in the discourse through the essay format, structure of ideas and arguments and use of rhetorical questions and academic vocabulary, was a major factor that influenced their discoursal self to be perceived as an inexperienced member of their academic community. Such portrayal of the students' discoursal self most likely resulted from their lack of awareness and knowledge of L2 academic writing culture, vocabulary and members of their academic community (i.e. the reader).

\section{Authorial self}

An authorial self portrays a writer's presence, ownership and authority over the arguments in the text (Burgess \& Ivanič, 2010). One common way for the students to establish individual identity and presence in the essays is by using the first-person pronoun $I$ (Ivanič \& Camps, 2001), which some students in this study also applied in their essays. However, from the discourse in the essays, it was found that these EFL novice writers tended to display authorial identities as a reporter and a biased judge. The authorial self was reflected in the student essays through the exposure of their own voice and others' voice, and the overall impact of the essays to the reader.

\section{Reporter}

In taking a stance in the essays, the students tended to position themselves in accordance with the mainstream or popular opinions. In the argumentative essay where they had to discuss whether or not global cooperation was necessary, all of them took the same stance by stating that it was indeed necessary; hence, in the essay, they presented evidence to show that global cooperation could help people solve some world problems. This can be seen from their topic sentence or thesis statement, as shown by S1, S2, S3, S5 and S8, respectively:

"I will tell you the reason why international cooperation is important."

"All countries in the world must cooperate together to prevent overpopulation."

"Every country in this world needs to join the UN because it brings many benefits."
"People hunger is an urgency to all countries in the world, which is why global cooperation at finding a helpful solution is needed."

"In this globalization era, global cooperation has become the urgency to deal with crucial issues."

With science and technology advancement, global cooperation is a common trend in this century. Many countries attempt to build and expand the network in various fields between one and another. Hence, the mainstream opinion spread in public is that global cooperation is positive and needs to be supported. In the essays, the students followed this popular opinion. One of the reasons was possibly due to the fact that the students were not used to disagree with or criticise ideas that have been well-established in society. In fact, some EFL learners from Asian countries, due to some cultural factors, may be trained not to challenge the ideas of their superiors (Lee \& Maguire, 2011). This could be a factor that caused a tendency for the students in this study to take a stance that followed popular opinions. As a result, their stance became predictable and, when not discussed properly, may present little internal process of critical thinking.

In L2 academic writing, writers need to take a stance in delivering a personal view; this is called a writer's voice (Hyland, 2008). The voice is essential in academic writing as it is the evidence of the writer's participation in the discussion as an academic community member through the written discourse. In the student essays, however, the stance, or the writer's voice, was not properly followed by a discussion from the students' original thinking of the topic. Instead, as mentioned in the interview, once they decided on a topic, they used to browse information online or in books, collected some of it and reported it in their essays. This practice, in which students participate in the topic discussion mostly by displaying and approving others' voice from other sources instead of elaborating their own thinking process, is known as patchwriting (Pecorari, 2003; McKinley, 2015). As the students mostly displayed others' voice in a reporting manner, e.g. by summarising and repeating descriptive and factual information, this may lead the reader to perceive them more as a reporter than as a writer who could establish his or her authority and presence in the essay content (Javdan, 2014; Starfield, 2002). This is in line with the literature (e.g. Bird, 2013; McKinley, 2015) that show that novice writers tend to use others' claims to direct the knowledge-making process in their essays, thus allowing others' voice to have more authority in their essays.

\section{Biased judge}

In L2 academic writing, writers are generally required to present a topic or issue from more than one perspective; it is essential for them to acknowledge and consider those views in discussing the subject matter with the reader as the reader may have different views than the writer (Wingate, 2012). Often, the views consist of a supporting view (argument) and an opposing view 
(counterargument). From the essays, it was found that despite showing an argument and a counterargument, some students failed to discuss the views evenly and logically, thus creating a perception of themselves as a biased judge and less credible writer to the reader. An instance of this can be seen in an excerpt of the persuasive essay written by $\mathrm{S} 2$, who intended to persuade the reader that drinking milk was a healthy habit:

"There are many benefits that we can get from drinking milk, but many people have a wrong perception about it. Many people especially teenagers and adults think that drinking milk is embarrassing because they think milk is only for little children. When they are thirsty, they prefer soda or coffee instead of milk."

In the excerpt, S2 showed his argument by stating that drinking milk was beneficial for many age groups, i.e. children, teenagers and adults. Ensuing the argument, he showed a counterargument that opposed his voice on the subject matter, i.e. 'teenagers and adults think that drinking milk is embarrassing...'. After stating this counterargument, he did not provide further explanation for it in the essay. The counterargument was then only stated and not justified, while his voice (argument) was being elaborated in the essay. From this, it can be seen that both the argument and the counterargument presented by S2 were not evenly discussed, let alone logically justified (for the counterargument). As a result, this may lead the reader to think that the student was highly biased towards his own argument and judgmental towards the opposite view.

Moreover, there are possible reasons for teenagers and adults not to drink milk, but the sole reason stated in the excerpt seems to be minor and opinionated as it was not justified by any evidence. In many parts of the world, including Indonesia, milk is a popular healthy drink for babies, children, teenagers, adults and elders. In fact, various types of milk are produced to meet diverse health needs of its consumers based on their age. As the student showed a counterargument but failed to give a logical explanation for it, this particular part in his essay may appear to be confusing and less convincing to the reader (Intaraprawat \& Steffensen, 1995).

In addition, from the excerpt, it can be noticed that the student made claims by using a booster of many people. In academic writing, it is important for writers to present information accurately (Wingate, 2012). The student did not specify his context of many people in his claims; thus, the claims seem like his own assumption and judgment.

The authorial role identities in the essays portrayed emotive expression that was often opinionated and biased. Thus, the essays may affect the reader mostly on the affective level instead of cognitive level since the students' discourse tended to appeal to emotions rather than to logical thinking and reasonable discussion on the subject matter. In L2 academic writing culture, both opinions and emotions must always be balanced with reasons in order to avoid creating a discourse that is perceived as opinionated or ambiguous by the members of the academic community (Rahimivand \& Kuhi, 2014).

\section{CONCLUSION}

This study explores the academic identities reflected in the L2 academic writing of EFL novice writers in undergraduate level. The findings revealed that these students reflected multifaceted academic identities, i.e. average university student, experienced and knowledgeable person, novice member of the academic community, reporter and biased judge. Beneath the portrayal of the identities, the findings of this study also support some studies (e.g. Angélil-Carter, 2000; Cameron et al., 2009; Hutchings, 2013; Scanlon et al., 2007) that report that novice writers tend to struggle to adjust and engage themselves in L2 academic writing practice due to some factors, e.g. the lack of exposure, familiarity and understanding towards L2 academic environment, academic writing culture and academic community. As a result, it affected the students to have weak identity reflection as members of their academic community (Bird, 2013). Nonetheless, as this study was conducted in one research site with only a few students, these findings cannot be used to represent Indonesians or EFL novice writers in general.

Several recommendations that the study draws from the findings regarding L2 Writing instruction for EFL novice writers in higher education include: teaching the core concepts of L2 academic writing and its culture so that students will have a wide-ranging knowledge on it, adding more focus on the development of students' cognition, e.g. logical and critical thinking, and facilitating students to develop their own intrinsic motivation in L2 academic writing, e.g. by conducting regular academic discussions in the class or incorporating peer-review and writing conference with more experienced academic community members. As EFL novice writers get more exposure to the academic culture in their own discipline through active and meaningful learning participation, their writing experience and writer identities may as well be enriched and fostered (Liming, 2012).

\section{ACKNOWLEDGEMENTS}

This study was conducted with the financial support provided by the Center for Research and Community Service, Universitas Kristen Krida Wacana.

\section{REFERENCES}

Angélil-Carter, S. (2000). Stolen language? Plagiarism in writing. Harlow, UK: Pearson Education.

Bird, B. (2013). A basic writing course design to promote writer identity: Three analyses of student papers. Journal of Basic Writing, 32(1), 62-96.

Burgess, A. \& Ivanič, R. (2010). Writing and being written: Issues of identity across timescales. Written Communication, 27(2), 228-255. doi: $10.1177 \% 2 F 0741088310363447$

Cameron, J., Nairn, K. \& Higgins, J. (2009). Demystifying academic writing: Reflections on emotions, know-how and academic identity. 
Journal of Geography in Higher Education, 33(2), 269-284. doi: 10.1080/03098260902734943

Cimasko, T. \& Reichelt, M. (2011). Eds. Foreign language writing instruction: Principles and practices. Anderson, SC: Parlor Press.

Crawford, T., Pablo, I. M. \& Lengeling, M. M. (2016). Struggling authorial identity of second language university academic writers in Mexico. Profile: Issues in Teachers' Professional Development, 18(1), 115-127. doi: 10.15446/profile.v18n1.48000

De Haan, P. \& van der Haagen, M. (2013). Assessing the use of sophisticated EFL writing. Writing Assessment in Higher Education, 2(1), 16-27. doi: 10.1075/dujal.2.1.04deh

Erkan, D. Y. \& Saban, A. I. (2011). Writing performance relative to writing apprehension, selfefficacy in writing, and attitudes towards writing: A correlational study in Turkish-tertiary level EFL. Asian EFL Journal, 13(1), 164-192.

Fareed, M., Ashraf, A. \& Bilal, M. (2016). ESL learners' writing skills: Problems, factors and suggestions. Journal of Education and Social Sciences, 4(2), 81-92. doi: 10.20547/jess0421604201

Flick, U. (2014). An introduction to qualitative research. $\left(5^{\text {th }}\right.$ ed.). London: SAGE Publications Ltd.

Gillam, K. \& Wooden, S. R. (2013). Re-embodying online composition: Ecologies of writing in unreal time and space. Computers and Composition, 30(1), 24-36. doi: 10.1016/j.compcom.2012.11.001

Hinkel, E. (1997). Indirectness in L1 and L2 academic writing. Journal of Pragmatics, 27(3), 361-386. doi: 10.1016/S0378-2166(96)00040-9

Hutchings, C. (2013). Referencing and identity, voice and agency: adult learners' transformations within literacy practices. Higher Education Research \& Development, 33(2), 312-324. doi: $10.1080 / 07294360.2013 .832159$

Hyland, K. (2002a). Options of identity in academic writing. ELT Journal, 56(4), 351-358. doi: 10.1093/elt/56.4.351

Hyland, K. (2002b). What do they mean? Questions in academic writing. Text - Interdisciplinary Journal for the Study of Discourse, 22(4), 529-557. doi: $10.1515 /$ text.2002.021

Hyland, K. (2005). Metadiscourse: Exploring interaction in writing. London: Continuum.

Hyland, K. (2008). Disciplinary voices: Interactions in research writing. English Text Construction, 1(1), 5-22. doi: 10.1075/etc.1.1.03hyl

Hyland, K. (2009). Academic discourse: English in a global context. London: Continuum.

Hyland, K. (2010). Metadiscourse: Mapping interactions in academic writing. Nordic Journal of English Studies, 9(2), 125-143. doi: 10.35360/njes. 220

Intaraprawat, P. \& Steffensen, M. S. (1995). The use of metadiscourse in good and poor ESL essays.
Journal of Second Language Writing, 4(3), 253272. doi: 10.1016/1060-3743(95)90012-8

Ivanič, R. (1994). I is for interpersonal: Discoursal construction of writer identities and the teaching of writing. Linguistics and Education, 6(1), 3-15. doi: 10.1016/0898-5898(94)90018-3

Ivanič, R. (1998). Writing and identity: The discoursal construction of identity in academic writing. Philadelphia, PA: John Benjamins Publishing Company.

Ivanič, R. \& Camps, D. (2001). I am how I sound: Voice as self-representation in L2 writing. Journal of Second Language Writing, 10(1-2), 3-33. doi: 10.1016/S1060-3743(01)00034-0

Javdan, S. (2014). Identity manifestation in second language writing through notion of voice: A review of literature. Theory and Practice in Language Studies, 4(3), 631-635. doi: 10.4304/tpls.4.3.631-635

Jiang, X. (2011). Challenges for college-level learners of academic English writing in China. In M. S. Plakhotnik, S. M. Nielsen \& D. M. Pane (Eds.), Proceedings of the Tenth Annual College of Education \& GSN Research Conference, 95-100. Miami: Florida International University.

Jones, J. F. (2011). Using metadiscourse to improve coherence in academic writing. Language Education in Asia, 2(1), 1-14. doi: 10.5746/leia/11/v2/i1/a01/jfjones

Kubota, R. (2001). Discursive construction of the images of US classrooms. TESOL Quarterly, 35(1), 9-38. doi: 10.2307/3587858

Kuntjara, E. (2004). Cultural transfer in EFL writing: A look at contrastive rhetoric on English and Indonesian. K@ta: A Biannual Publication on the Study of Language and Literature, 6(1), 13-29. doi: 10.9744/kata.6.1.13-29

Lee, H. \& Maguire, M. H. (2011). International students and identity: Resisting dominant ways of writing and knowing in academe. In D. Starke-Meyerring, A. Paré, N. Artemava, M. Horne \& L. Yousouhova (Eds.), Writing in Knowledge Societies, 351-370. Parlor Press and WAC Claringhouse.

Liming, D. (2012). Academic identity construction in writing the discussion \& cnclusion section of L2 theses: Case studies of Chinese social science doctoral students. Chinese Journal of Applied Linguistics (Quarterly), 35(3), 301-323. doi: 10.1515/cjal-2012-0023

Liu, X. \& Furneaux, C. (2013). A multidimensional comparison of discourse organization in English and Chinese university students' argumentative writing. International Journal of Applied Linguistics, 24(1), 74-96. doi: 10.1111/ijal.12013

McKinley, J. (2015). Critical argument and writer identity: Social constructivism as a theoretical framework for EFL academic writing. Critical Inquiry in Language Studies, 12(3), 184-207. doi: 10.1080/15427587.2015.1060558 
Morley-Warner, T. (2009). Academic writing is...; A guide to writing in a university context. Sydney, Australia: Association for Academic Language and Learning.

North, S. (2005). Different values, different skills? A comparison of essay writing by students from arts and science backgrounds. Studies in Higher Education, 30(5), 517-533. doi: $10.1080 / 03075070500249153$

Okasha, M. A. \& Hamdi, S. A. (2014). Using strategic writing techniques for promoting EFL writing skills and attitudes. Journal of Language Teaching and Research, 5(3), 674-681. doi: 10.4304/jltr.5.3.674-681

Park, G. (2013). 'Writing is a way of knowing': writing and identity. ELT Journal, 67(3), 336-345. doi: 10.1093/elt/cct012

Pecorari, D. (2003). Good and original: Plagiarism and patchwriting in academic second-language writing. Journal of Second Language Writing, 12(4), 317345. doi: 10.1016/j.jslw.2003.08.004

Petrić, B. (2005). Contrastive rhetoric in the writing classroom: A case study. English for Specific Purposes, 24(2), 213-228. doi: 10.1016/j.esp.2004.09.001

Qin, C. L. (2017). The impact of cultural thought patterns upon English writing. Cross-Cultural Communication, 13(10), 10-13. doi: $10.3968 / 10144$

Rahimivand, M. \& Kuhi, D. (2014). An exploration of discoursal construction of identity in academic writing. Procedia - Social and Behavioral
Sciences, 98, 1492-1501. doi: 10.1016/j.sbspro.2014.03.570

Rahman, M. S. (2017). The advantages and disadvantages of using qualitative and quantitative approaches and methods in language "testing and assessment" research: A literature review. Journal of Education and Learning, 6(1), 102-112. doi: 10.5539/jel.v6n1p102

Scanlon, L., Rowling, L. \& Weber, Z. (2007). 'You don't have like an identity... you are just lost in a crowd': Forming a student identity in the first-year transition to university. Journal of Youth Studies, 10(2), 223-241. doi: 10.1080/13676260600983684

Schneer, D. (2013). Rethinking the argumentative essay. TESOL Journal, 5(4), 619-653. doi: 10.1002/tesj.123

Shang, H. (2013). Factors associated with English as a foreign language university students writing anxiety. International Journal of English Language Teaching, 1(1), 1-12. doi: 10.1111/j.1944-9720.2002.tb01903.x

Starfield, S. (2002). 'I'm a second-language English speaker": Negotiating writer identity and authority in Sociology One. Journal of Language, Identity \& Education, 1(2), 121-140. doi: 10.1207/S15327701JLIE0102_02

Steinman, L. (2003). Cultural collisions in L2 academic writing. TESL Canada Journal, 20(2), 80-91. doi: 10.18806/tesl.v20i2.950

Wingate, U. (2012). “Argument!” Helping students understand what essay writing is about. Journal of English for Academic Purposes, 11(2), 145-154. doi: 10.1016/j.jeap.2011.11.001 